\title{
Long-term effects of beta-blocker use on lung function in Japanese patients with chronic obstructive pulmonary disease
}

This article was published in the following Dove Press journal:

International Journal of COPD

10 April 2017

Number of times this article has been viewed

\author{
Naohiro Oda' \\ Nobuaki Miyahara ${ }^{1,2}$ \\ Hirohisa Ichikawa ${ }^{3}$ \\ Yasushi Tanimoto ${ }^{4}$ \\ Kazuhiro Kajimoto ${ }^{5}$ \\ Makoto Sakugawa ${ }^{6}$ \\ Haruyuki Kawai ${ }^{7}$ \\ Akihiko Taniguchi' \\ Daisuke Morichika' \\ Mitsune Tanimoto' \\ Arihiko Kanehiro' \\ Katsuyuki Kiura' \\ 'Department of Allergy and \\ Respiratory Medicine, Okayama \\ University Hospital, ${ }^{2}$ Department \\ of Medical Technology, Okayama \\ University Graduate School of Health \\ Sciences, Okayama, ${ }^{3}$ Department \\ of Respiratory Medicine, KKR \\ Takamatsu Hospital, Takamatsu, \\ ${ }^{4}$ Department of Respiratory Medicine, \\ National Hospital Organization \\ Minami-Okayama Medical Center, \\ Okayama, ${ }^{5}$ Department of \\ Respiratory Medicine, Kobe Red \\ Cross Hospital, Kobe, ${ }^{6}$ Department \\ of Respiratory Medicine, Okayama \\ Red Cross Hospital, ${ }^{7}$ Department \\ of Respiratory Medicine, Okayama \\ Saiseikai Hospital, Okayama, Japan
}

Correspondence: Nobuaki Miyahara Department of Medical Technology, Okayama University Graduate School of Health Sciences, 2-5-I Shikata-cho

Kita-ku, Okayama 700-0914, Japan

Tel +8I 862357227

Fax +8I 862328226

Email miyahara@okayama-u.ac.jp
Background: Some recent studies have suggested that beta-blocker use in patients with chronic obstructive pulmonary disease (COPD) is associated with a reduction in the frequency of acute exacerbations. However, the long-term effects of beta-blocker use on lung function of COPD patients have hardly been evaluated.

Patients and methods: We retrospectively reviewed 31 Japanese COPD patients taking betablockers for $>1$ year and 72 patients not taking them. The association between beta-blocker use and the annual change in forced expiratory volume in 1 second (FEV1) was assessed.

Results: At baseline, patient demographic characteristics were as follows: 97 males (mean age 67.0 \pm 8.2 years); 32 current smokers; and Global Initiative for Chronic Obstructive Lung disease (GOLD) stages I: $\mathrm{n}=26$, II: $\mathrm{n}=52$, III: $\mathrm{n}=19$, and IV: $\mathrm{n}=6$. Patients taking beta-blockers exhibited a significantly lower forced vital capacity (FVC), FEV1, and \%FVC, and a more advanced GOLD stage. The mean duration of beta-blocker administration was $2.8 \pm 1.7$ years. There were no differences in the annual change in FEV1 between patients who did and did not use beta-blockers $(-7.6 \pm 93.5 \mathrm{~mL} /$ year vs $-4.7 \pm 118.9 \mathrm{~mL} /$ year, $P=0.671)$. After controlling for relevant confounders in multivariate analyses, it was found that beta-blocker use was not significantly associated with the annual decline in FEV1 ( $\beta=-0.019 ; 95 \%$ confidence interval: -0.073 to $0.036 ; P=0.503$ ).

Conclusion: Long-term beta-blocker use in Japanese COPD patients might not affect the FEV1, one of the most important parameters of lung function in COPD patients.

Keywords: chronic obstructive pulmonary disease, beta-blocker, lung function, spirometry, forced expiratory volume in 1 second, long-term

\section{Introduction}

Chronic obstructive pulmonary disease (COPD) is an inflammatory pulmonary condition caused by long-term inhalation and/or exposure to hazardous substances represented by cigarette smoke, triggering incurable airflow obstruction as evidenced in lung function tests. ${ }^{1}$ The incidence of COPD is increasing worldwide, and it is predicted that, by 2020, COPD will be the fifth most prominent cause of morbidity and the third leading cause of mortality. ${ }^{2}$ COPD patients usually exhibit various systemic complications, typically cardiovascular disease. Morbidity associated with cardiovascular disease is fivefold more common in COPD than non-COPD patients; ${ }^{3}$ cardiovascular diseases including heart failure and coronary artery disease (CAD) are responsible for $>27 \%$ of all mortality of patients with moderate-to-severe COPD. ${ }^{4}$ Thus, cardiovascular disease seriously compromises the prognosis of COPD patients.

Large-scale clinical studies have shown that beta-blockers reduce the complication rates and mortality that may develop secondarily to heart failure and CAD., ${ }^{5,6}$ 
Therefore, beta-blockers are often prescribed for COPD patients at high risk for the complications of cardiovascular disease. However, some clinicians tend to avoid prescribing beta-blockers for COPD patients, for fear of adverse effects including bronchospasm and reduced lung function. ${ }^{7} \mathrm{~A}$ few retrospective studies have found that beta-blocker use was associated with reduced mortality of, and less acute exacerbation in, COPD patients. ${ }^{8-10}$ Although these studies primarily enrolled COPD patients with cardiovascular complications, it has also been reported that beta-blockers inhibit acute exacerbation, independent of both cardiovascular disease status and the use of other cardiac drugs. ${ }^{10}$ Thus, the possible benefits of beta-blockers for COPD patients have attracted increasing attention. To date, the effects of cardioselective beta-blockers on lung function in COPD patients have been explored over timeframes of only a few months, and no significant clinical reductions in lung function have been reported. ${ }^{11}$ To the best of our knowledge, the longterm effects of beta-blockers on the lung function of COPD patients have hardly been examined.

The annual changes in the lung function of Japanese COPD patients taking beta-blockers were retrospectively evaluated.

\section{Patients and methods}

\section{Patients}

All enrolled subjects were COPD patients taking betablockers for $>1$ year who were regularly evaluated in the Okayama University Hospital, KKR Takamatsu Hospital, the National Hospital Organization Minami-Okayama Medical Center, the Kobe Red Cross Hospital, the Okayama Red Cross Hospital, and the Okayama Saiseikai Hospital, from January to December 2015. COPD was spirometrically diagnosed. The pre-bronchodilator ratio of the forced expiratory volume in 1 second (FEV1)/forced vital capacity (FVC) was $<70 \%{ }^{12,13}$ COPD patients $>40$ years of age were included if serial spirometric measurements obtained over $\geq 1$ year were available. Patients with lung cancer, a history of lung resection, or $<10$ pack-years of smoking history were excluded. The non-beta-blocker group included COPD patients not taking beta-blockers who visited Okayama University Hospital during the same period, and who also fulfilled the criteria described above.

\section{Study design}

Demographic and clinical data contained in medical records prepared after 2005 from the baseline to the time of final spirometry were retrospectively collected. The predicted spirometric data were those of the pulmonary function criteria of the Japanese Respiratory Society. ${ }^{14}$ COPD severity was classified as follows: Stage I: FEV1/predicted FEV1 $\geq 80 \%$; Stage II: $80 \%>$ FEV1/predicted FEV1 $\geq 50 \%$; Stage III: $50 \%>$ FEV $1 /$ predicted FEV $1 \geq 30 \%$ or $30 \%>$ FEV $1 /$ predicted FEV1. ${ }^{12}$ The primary endpoint was the annual change in FEV1. The study adhered to the principles of the Declaration of Helsinki and was approved by the Institutional Review Board (IRB) of Okayama University Hospital (no 1604-034) and the IRBs of all participating hospitals: KKR Takamatsu Hospital IRB, the National Hospital Organization Minami-Okayama Medical Center IRB, the Kobe Red Cross Hospital IRB, the Okayama Red Cross Hospital IRB, and the Okayama Saiseikai Hospital IRB. All clinical data collected from medical records were anonymized, and their confidentiality was covered. The IRB granted a waiver of written informed consent because this retrospective study provided information disclosure with a chance for opt-out.

\section{Statistical analysis}

Continuous variables are presented as mean \pm standard deviation (SD) and categorical variables are given as numbers with percentages. The significance of betweengroup differences was assessed by using Student's $t$-test or the Mann-Whitney test for continuous variables, and the Chi-squared test was used for categorical variables. The association between beta-blocker use and annual changes in lung function was assessed via multivariate linear regression modeling adjusted for confounding factors (age, sex, smoking status, body mass index [BMI], initial \%FEV1, asthma COPD overlap syndrome [ACOS], cardiovascular disease, and acute exacerbation during the observational period). A $P$-value $<0.05$ was considered to reflect statistical significance. All statistical analyses were performed with the aid of STATA ver. 11.0 software (StataCorp, College Station, TX, USA).

\section{Results}

\section{Patient characteristics}

The characteristics of 103 COPD patients recorded at the time of baseline spirometry are summarized in Table 1 . The mean patient age was $67.0 \pm 8.2$ years, and $94.2 \%$ were male. The 31 patients taking beta-blockers had significantly lower FVC, FEV1, and \%FVC values and were of poorer Global Initiative for Chronic Obstructive Lung disease (GOLD) stage. There were no differences in age, sex, BMI, smoking status (pack-years), home oxygen therapy administration rate, or ACOS status between the two groups. 
Table I Demographic data on 103 COPD patients who did or did not take beta-blockers

\begin{tabular}{|c|c|c|c|c|}
\hline & Total & Beta-blocker use & No beta-blocker use & $P$-value \\
\hline & $n=103$ & $n=3 \mathbf{I}$ & $n=72$ & \\
\hline Age (mean [SD]), year & $67.0(8.2)$ & $68.2(9.8)$ & $67.0(7.5)$ & 0.501 \\
\hline Sex (male/female) & $97(94 \%) / 6(6 \%)$ & $30(97 \%) / I(3 \%)$ & $67(93 \%) / 5(7 \%)$ & 0.460 \\
\hline Smoking status (current/former) & $32(3 \mid \%) / 7 \mid(69 \%)$ & $6(19 \%) / 25(81 \%)$ & $26(36 \%) / 46(64 \%)$ & 0.092 \\
\hline Pack-years (mean [SD]) & $57.1(32.3)$ & $60.0(32.3)$ & $55.8(32.4)$ & 0.420 \\
\hline Body mass index (mean $[S D]$ ), $\mathrm{kg} / \mathrm{m}^{2}$ & $23.1(3.6)$ & $23.1(3.8)$ & $23.1(3.6)$ & 0.970 \\
\hline Home oxygen therapy & $5(5 \%)$ & $3(10 \%)$ & $2(3 \%)$ & 0.135 \\
\hline \multirow[t]{2}{*}{ GOLD stage $(1 / 2 / 3 / 4)$} & $26(25 \%) / 52(51 \%) /$ & $4(13 \%) / / 8(58 \%) /$ & $22(31 \%) / 34(47 \%) /$ & 0.049 \\
\hline & $19(18 \%) / 6(6 \%)$ & $5(16 \%) / 4(13 \%)$ & $14(19 \%) / 2(3 \%)$ & \\
\hline FVC (mean [SD]), L & $3.25(0.86)$ & $2.93(0.8 I)$ & $3.39(0.86)$ & 0.014 \\
\hline \%FVC (mean [SD]), \% & $91.6(20.9)$ & $82.7(18.8)$ & $95.4(20.7)$ & 0.004 \\
\hline FEVI (mean [SD]), L & $1.83(0.65)$ & $\mathrm{I} .64(0.59)$ & $1.91(0.66)$ & 0.041 \\
\hline \%FEVI (mean [SD]), \% & $65.2(21.7)$ & $58.9(19.0)$ & $67.9(22.4)$ & 0.054 \\
\hline FEVI/FVC ratio (mean [SD]), \% & $55.5(11.2)$ & $55.5(11.5)$ & $54.5($ (II.I) & 0.989 \\
\hline Asthma-COPD overlap syndrome & $25(24 \%)$ & $6(19 \%)$ & $19(26 \%)$ & 0.445 \\
\hline
\end{tabular}

Abbreviations: COPD, chronic obstructive pulmonary disease; SD, standard deviation; GOLD, Global Initiative for Chronic Obstructive Lung Disease; FEVI, forced expiratory volume in I second; FVC, forced vital capacity.

\section{Clinical course}

The mean observational period was $4.1 \pm 2.5$ years. Eighteen patients took cardioselective beta-blockers (12 bisoprolol and 6 atenolol), and 13 were prescribed the non-cardioselective beta-blocker carvedilol. Of the 31 patients taking beta-blockers, 14 commenced treatment during the observational period, but 17 had commenced treatment prior to study commencement. The mean duration of beta-blocker usage was $2.8 \pm 1.7$ years. Patients on betablockers were more likely to have underlying $\mathrm{CAD}$, chronic heart failure (CHF), atrial fibrillation, and hypertension than other patients (Table 2).

Neither the medications prescribed to treat COPD nor the frequencies of severe exacerbations requiring hospitalization during the observational period differed significantly between the two groups. Annual changes in lung function are summarized in Table 3. The annual change in FEV1 was $-5.5 \pm 111.4 \mathrm{~mL} /$ year. The annual changes in FEV1 did not differ between patients who did and did not take beta-blockers $(-7.6 \pm 93.5 \mathrm{~mL} /$ year vs $-4.7 \pm 118.9 \mathrm{~mL} /$ year, $P=0.671)$ (Figure 1). No differences in the annual changes in the \%FEV1 were evident between the two groups. After controlling for relevant confounders in multivariate analyses, beta-blocker use was not significantly associated with the annual decline in FEV1 (Table 4). Of the confounders, if the baseline \%FEV1 predicted was higher, the annual decline of FEV1 was greater $(\beta=-0.002 ; 95 \%$ confidence interval $[\mathrm{CI}]-0.003$ to -0.001 ; $P=0.002)$. The annual decline in FEV1 tended to be smaller in ACOS patients, although statistical significance was not attained ( $\beta=0.044 ; 95 \%$ CI: -0.008 to $0.096 ; P=0.098$ ).

Table 2 Cardiac comorbidities, acute exacerbation, and medications used to treat COPD during follow-up

\begin{tabular}{|c|c|c|c|c|}
\hline & Total & Beta-blocker use & No beta-blocker use & $P$-value \\
\hline & $n=103$ & $n=31$ & $n=72$ & \\
\hline Observational period (mean $[S D]$ ), years & $4.1(2.5)$ & $3.5(2.0)$ & $4.4(2.7)$ & 0.148 \\
\hline \multicolumn{5}{|l|}{ Cardiac comorbidities } \\
\hline Coronary artery disease & $18(18 \%)$ & $12(39 \%)$ & $6(8 \%)$ & $<0.001$ \\
\hline Chronic heart failure & $17(17 \%)$ & 14 (45\%) & $3(4 \%)$ & $<0.001$ \\
\hline Atrial fibrillation & $17(17 \%)$ & $12(39 \%)$ & $5(7 \%)$ & $<0.001$ \\
\hline Hypertension & 51 (50\%) & $23(74 \%)$ & $28(39 \%)$ & 0.001 \\
\hline Acute exacerbation & 14 (|4\%) & $5(16 \%)$ & $9(13 \%)$ & 0.622 \\
\hline \multicolumn{5}{|l|}{ Medications for COPD } \\
\hline Long-acting muscarinic antagonist & $65(63 \%)$ & $22(71 \%)$ & $43(60 \%)$ & 0.278 \\
\hline Long-acting beta adrenoceptor agonist & $59(57 \%)$ & 17 (55\%) & $42(58 \%)$ & 0.742 \\
\hline Inhaled corticosteroid & 37 (36\%) & 13 (42\%) & $24(33 \%)$ & 0.404 \\
\hline Any inhalation therapy* & 85 (83\%) & 26 (84\%) & 59 (82\%) & 0.813 \\
\hline
\end{tabular}

Note: *Any inhalation therapy: a long-acting muscarinic antagonist, a long-acting beta adrenoceptor agonist, or an inhaled corticosteroid. Abbreviations: COPD, chronic obstructive pulmonary disease; SD, standard deviation. 
Table 3 Annual changes in lung function in COPD patients with or without treatment with beta-blockers

\begin{tabular}{|c|c|c|c|c|}
\hline & Total & Beta-blocker use & No beta-blocker use & $P$-value \\
\hline & $n=103$ & $n=31$ & $n=72$ & \\
\hline Observational period (mean $[\mathrm{SD}]$ ), years & $4.1(2.5)$ & $3.5(2.0)$ & $4.4(2.7)$ & 0.148 \\
\hline Annual change in the FEVI (mean $[S D]$ ), mL/year & $-5.5(111.4)$ & $-7.6(93.5)$ & $-4.7(|| 8.9)$ & 0.671 \\
\hline Annual change in the \%FEVI (mean [SD]), \%/year & $0.50(4.09)$ & $0.50(3.55)$ & $0.50(4.32)$ & 0.757 \\
\hline
\end{tabular}

Abbreviations: COPD, chronic obstructive pulmonary disease; SD, standard deviation; FEVI, forced expiratory volume in I second.

Differences in the annual changes in FEV1 attributable to treatment combinations were explored. Of patients using beta-blockers, those on any COPD inhalation therapy tended to exhibit a lower annual decline in FEV1 than did the other patients, although statistical significance was not attained (Table 5).

\section{Discussion}

Annual changes in the lung function of Japanese COPD patients taking and not taking beta-blockers were retrospectively compared, and it was found that the decline in FEV1 did not differ significantly between the two groups. Multivariate analyses, after adjusting for several confounding factors, confirmed that beta-blocker use did not compromise the FEV1 of COPD patients. Thus, in Japanese COPD patients, beta-blocker use might not affect the FEV1, one of the most important pulmonary function parameters in COPD patients.

The FEV1 declines over time. ${ }^{15}$ Changes in FEV1 in COPD patients are variable, ranging from $-40 \mathrm{~mL} / \mathrm{year}$ to $20 \mathrm{~mL} /$ year in a large observational study. ${ }^{16} \mathrm{~A}$ recent systematic review reported that a cardioselective betablocker with an affinity 20 -fold greater for beta- 1 than beta- 2 adrenoceptors was theoretically associated with a lower

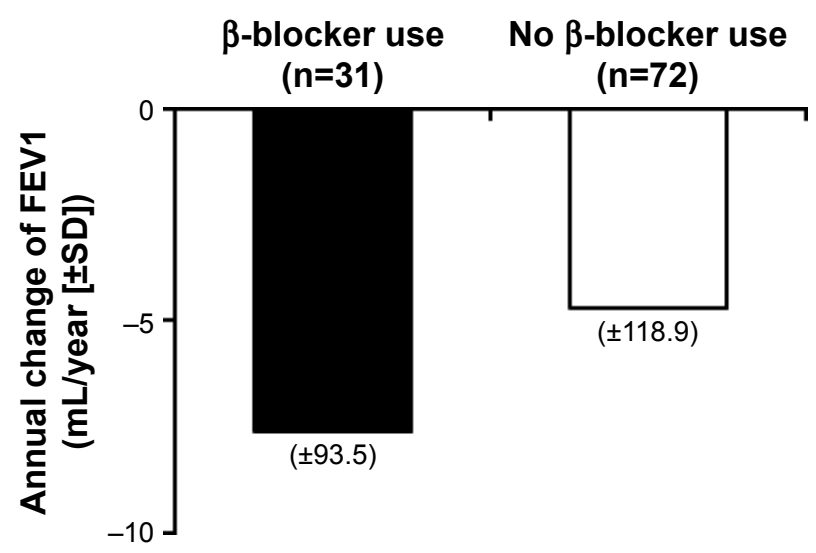

Figure I Annual changes in FEVI levels in COPD patients with or without treatment with beta-blockers.

Abbreviations: COPD, chronic obstructive pulmonary disease; FEVI, forced expiratory volume in I second. risk for bronchospasm and did not cause any significant deterioration in the FEV1, compared to placebo. ${ }^{11}$ The studies reviewed in the present report administered beta-blockers for 2 days to 16 weeks. Our mean duration of administration was $2.8 \pm 1.7$ years; thus, the authors were able to evaluate long-term effects. One prior, large population-based study explored the effects of beta-blockers on lung function. ${ }^{17}$ The mean observational period was $6.1 \pm 0.5$ years; over this time, the FEV1 decreased significantly in those given cardioselective beta-blockers compared to patients who did not receive them $(-13.5 \%$ vs $-9.4 \%)$. However, only $16.7 \%$ of patients had COPD. By contrast, in another study, most patients who used beta-blockers had COPD, and the decrease in FEV1 in these patients was not obviously lower than that of the historical control. ${ }^{10}$ In that study, a large database on COPD patients was used; $65.3 \%$ of those treated with betablockers also received some type of inhalation therapy for COPD including long-acting muscarinic antagonists, longacting beta adrenoceptor agonists, inhaled corticosteroids, or combinations thereof. Similarly, in this study, $83.9 \%$ of patients treated with beta-blockers received some type of inhalation therapy for COPD. As shown in Table 5, such therapy tended to suppress the annual decline in FEV1 even when beta-blockers were prescribed. Thus, appropriate

Table 4 Multivariate analyses of the annual decline in FEVI

\begin{tabular}{lll}
\hline & $B(95 \% \mathbf{C l})$ & $P$-value \\
\hline Beta-blocker use (yes vs no) & $-0.019(-0.073$ to 0.036$)$ & 0.503 \\
Age & $0.00 I(-0.002$ to 0.004$)$ & 0.436 \\
Sex (male vs female) & $-0.032(-0.129$ to 0.064$)$ & 0.506 \\
Smoking status (current vs former) & $-0.012(-0.063$ to 0.040$)$ & 0.658 \\
Body mass index ( $\geq 2$ I vs & $-0.00 I(-0.047$ to 0.049$)$ & 0.979 \\
$<2$ I kg/m $\left.\mathrm{m}^{2}\right)$ & & \\
Initial \%FEVI & $-0.002(-0.003$ to $-0.00 \mathrm{I})$ & 0.002 \\
Asthma-COPD overlap syndrome & $0.044(-0.008$ to 0.096$)$ & 0.098 \\
(yes vs no) & & \\
Cardiovascular disease* (yes vs no) & $-0.00 I(-0.059$ to 0.058$)$ & 0.985 \\
Acute exacerbation during & $-0.026(-0.095$ to 0.042$)$ & 0.452 \\
follow-up (yes vs no) & & \\
\hline
\end{tabular}

Notes: Response variable: annual change in FEVI (L/year). *Coronary artery disease or chronic heart failure.

Abbreviations: COPD, chronic obstructive pulmonary disease; FEVI, forced expiratory volume in I second; $\mathrm{Cl}$, confidence interval. 
Table 5 Annual changes in FEVI levels in patients taking betablockers, with or without inhalation therapy

\begin{tabular}{lll}
\hline $\begin{array}{l}\text { Inhalation } \\
\text { therapy* }\end{array}$ & $\mathbf{n}$ & $\begin{array}{l}\text { Annual change in FEV I } \\
\text { (mean [SD]); mL/year }\end{array}$ \\
\hline No & 5 & $-33.8(54.2)$ \\
Yes & 26 & $-2.6(99.2)$ \\
\hline
\end{tabular}

Note: *Inhalation therapy: a long-acting muscarinic antagonist, a long-acting beta adrenoceptor agonist, or an inhaled corticosteroid.

Abbreviations: FEVI, forced expiratory volume in I second; SD, standard deviation

inhalation therapy might render it possible to prevent any adverse effects on lung function caused by long-term administration of beta-blockers. In this study, there was no difference in annual change of FEV1 between cardioselective and non-cardioselective beta-blocker use (data not shown). All of the non-cardioselective beta-blockers used in this study were carvedilol. Carvedilol is relatively tolerable for COPD patients by promoting alfa-adrenergic blockade-induced mild bronchodilation. ${ }^{18}$ Thus, carvedilol might not suppress FEV1 in COPD patients.

In animal experiments, chronic administration of betablockers upregulates beta adrenoceptor levels in the lung, ${ }^{19}$ suppressing bronchospasm. ${ }^{20}$ Chronic administration of beta-blockers also suppresses airway inflammation and mucin production..$^{21}$ Thus, long-term administration of betablockers may have pathophysiological effects on the lung that differ from those seen upon short-term administration, suppressing bronchial constriction and airway inflammation. To investigate the long-term effects of beta-blockers on COPD patients, the authors are currently engaged in a 2-year prospective study using bisoprolol (UMIN registration number 000024712).

Many risk factors affecting the annual decline in the FEV1 of COPD patients have been reported to date; these include smoking, ${ }^{16,22,23}$ acute exacerbations, ${ }^{16,22}$ bronchodilator reversibility, ${ }^{16}$ emphysema, ${ }^{16,24} \mathrm{BMI},{ }^{25}$ and age.${ }^{26}$ In the present study, beta-blocker use was not significantly correlated with the annual decline in FEV1, even in multivariate analyses adjusted for relevant confounders, suggesting that beta-blocker use does not affect the annual decline in the FEV1 of COPD patients. On the other hand, when the baseline \%FEV1 value was higher, the annual decline in FEV1 was greater. In other words, those exhibiting a greater decline in FEV1 had milder disease. This trend is similar to that observed in other studies. ${ }^{16,25}$

Our study had several limitations. First, all analyses were retrospective, and our sample size was small, restricting the statistical power of our findings. Furthermore, as only patients in whom lung function had been continuously followed-up were enrolled, some selection bias may have been in play. Second, detailed information on cardiac function is lacking; control of concomitant cardiovascular disease might affect lung function. Third, the annual changes in FEV1 using the pre-bronchodilator FEV1 values were calculated. In patients with severe COPD, the slopes of changes in post-bronchodilator FEV1 values over time were significantly steeper than those of pre-bronchodilator measurements. ${ }^{27}$ Thus, the annual declines in FEV1 may have been underestimated, particularly in patients given betablockers, because they had more severe disease than those who were not given beta-blockers. Therefore, a comparison of beta-blocker use and non-use in patients with COPD of similar severity may be required to clarify the effects of beta-blockers on the decline in FEV1.

In conclusion, no significant associations between longterm beta-blocker use and the annual decline in FEV1 were found. Thus, beta-blockers may be safe in COPD patients on appropriate inhalation therapy. Additional prospective studies are required to confirm these results.

\section{Acknowledgments}

The authors thank all study participants. All data interpretation and reporting are the sole responsibility of the authors. This study was supported by the Okayama Respiratory Disease Study Group.

\section{Author contributions}

NO and NM had full access to all data, are responsible for data integrity and the accuracy of analyses. All authors contributed toward data analysis, drafting and critically revising the paper, gave final approval of the version to be published, and agree to be accountable for all aspects of the work.

\section{Disclosure}

The authors have no conflicts of interest to report.

\section{References}

1. Vestbo J, Hurd SS, Agusti AG, et al. Global strategy for the diagnosis, management, and prevention of chronic obstructive pulmonary disease: GOLD executive summary. Am J Respir Crit Care Med. 2013;187: 347-365.

2. Brusselle GG, Joos GF, Bracke KR. New insights into the immunology of chronic obstructive pulmonary disease. Lancet. 2011;378 1015-1026.

3. Feary JR, Rodrigues LC, Smith CJ, Hubbard RB, Gibson JE. Prevalence of major comorbidities in subjects with COPD and incidence of myocardial infarction and stroke: a comprehensive analysis using data from primary care. Thorax. 2010;65:956-962.

4. Reed RM, Eberlein M, Girgis RE, et al. Coronary artery disease is under-diagnosed and under-treated in advanced lung disease. Am J Med. 2012;125:1228.e13-1228.e22. 
5. Lechat P, Packer M, Chalon S, Cucherat M, Arab T, Boissel JP. Clinical effects of beta-adrenergic blockade in chronic heart failure: a meta-analysis of double-blind, placebo-controlled, randomised trials. Circulation. 1998;98:1184-1191.

6. Hjalmarson A, Elmfeldt D, Herlitz J, et al. Effect on mortality of metoprolol in acute myocardial infarction: a double-blind randomised trial. Lancet. 1981;2:823-827.

7. Neef PA, McDonald CF, Burrell LM, Irving LB, Johnson DF, Steinfort DP. Beta-blockers are under-prescribed in patients with chronic obstructive pulmonary disease and co-morbid cardiac disease. Intern Med J. 2016;46:1336-1340.

8. Bhatt SP, Wells JM, Kinney GL, et al. $\beta$-Blockers are associated with a reduction in COPD exacerbations. Thorax. 2016;71:8-14.

9. Rutten FHI, Zuithoff NP, Hak E, Grobbee DE, Hoes AW. Beta-blockers may reduce mortality and risk of exacerbations in patients with chronic obstructive pulmonary disease. Arch Intern Med. 2010;170:880-887.

10. Short PM, Lipworth SI, Elder DH, Schembri S, Lipworth BJ. Effect of beta blockers in treatment of chronic obstructive pulmonary disease: a retrospective cohort study. BMJ. 2011;342:d2549.

11. Salpeter SR, Ormiston TM, Salpeter EE. Cardioselective beta-blockers for chronic obstructive pulmonary disease. Cochrane Database Syst Rev. 2005;4:CD003566.

12. Rabe KF, Hurd S, Anzueto A, et al. Global Initiative for Chronic Obstructive Lung Disease: Global strategy for the diagnosis, management, and prevention of chronic obstructive pulmonary disease-GOLD executive summary. Am J Respir Crit Care Med. 2007;176:532-555.

13. Ishikawa N, Hattori N, Kohno N, Kobayashi A, Hayamizu T, Johnson M. Airway inflammation in Japanese COPD patients compared with smoking and nonsmoking controls. Int J Chron Obstruct Pulmon Dis. 2015;10:185-192.

14. [Guideline of respiratory function tests: spirometry, flow-volume curve, diffusion capacity of the lung]. Nihon Kokyuki Gakkai Zasshi. 2004;Suppl:1-56. Japanese.

15. Fletcher $\mathrm{C}$, Peto $\mathrm{R}$. The natural history of chronic airflow obstruction. Br Med J. 1977;1:1645-1648.

16. Vestbo J, Edwards LD, Scanlon PD, et al. Changes in forced expiratory volume in 1 second over time in COPD. N Engl J Med. 2011;365: 1184-1192.
17. Loth DW, Brusselle GG, Lahousse L, Hofman A, Leufkens HG, Stricker BH. $\beta$-Adrenoceptor blockers and pulmonary function in the general population: The Rotterdam Study. Br J Clin Pharmacol. 2014;77:190-200.

18. Malerba M, Montuschi P, Radaeli A, Pirisi M. Role of beta-blockers in patients with COPD: current perspective. Drug Discov Today. 2015; 20:129-135.

19. Callaerts-Vegh Z, Evans KL, Dudekula N, et al. Effects of acute and chronic administration of beta-adrenoceptor ligands on airway function in a murine model of asthma. Proc Natl Acad Sci U S A. 2004; 101:4948-4953.

20. McGraw DW, Forbes SL, Mak JC, et al. Transgenic overexpression of beta (2)-adrenergic receptors in airway epithelial cells decreases bronchoconstriction. Am J Physiol Lung Cell Mol Physiol. 2000; 279:L379-L389.

21. Nguyen LP, Omoluabi O, Parra S, et al. Chronic exposure to betablockers attenuates inflammation and mucin content in a murine asthma model. Am J Respir Cell Mol Biol. 2008;38:256-262.

22. Kesten S, Celli B, Decramer M, Liu D, Tashkin D. Adverse health consequences in COPD patients with rapid decline in FEV1-evidence from the UPLIFT trial. Respir Res. 2011;12:129.

23. Anthonisen NR, Connett JE, Kiley JP, et al. Effects of smoking intervention and the use of an inhaled anticholinergic bronchodilator on the rate of decline of FEV1. The Lung Health Study. JAMA. 1994; 272(19):1497-1505.

24. Nishimura M, Makita H, Nagai K, et al. Annual change in pulmonary function and clinical phenotype in chronic obstructive pulmonary disease. Am J Respir Crit Care Med. 2012;185:44-52.

25. Casanova C, de Torres JP, Aguirre-Jaime A, et al. The progression of chronic obstructive pulmonary disease is heterogeneous: The experience of the BODE cohort. Am J Respir Crit Care Med. 2011;184: 1015-1021.

26. Kim SJ, Lee J, Park YS, et al. Age-related annual decline of lung function in patients with COPD. Int J Chron Obstruct Pulmon Dis. 2015;11: 51-60.

27. Tashkin DP, Li N, Halpin D, et al. Annual rates of change in pre- vs. post-bronchodilator FEV1 and FVC over 4 years in moderate to very severe COPD. Respir Med. 2013;107:1904-1911.
International Journal of COPD

\section{Publish your work in this journal}

The International Journal of COPD is an international, peer-reviewed journal of therapeutics and pharmacology focusing on concise rapid reporting of clinical studies and reviews in COPD. Special focus is given to the pathophysiological processes underlying the disease, intervention programs, patient focused education, and self management protocols.

\section{Dovepress}

This journal is indexed on PubMed Central, MedLine and CAS. The manuscript management system is completely online and includes a very quick and fair peer-review system, which is all easy to use. Visit http://www.dovepress.com/testimonials.php to read real quotes from published authors. 